\title{
Esperrància: O lugar da espera e da errância ${ }^{*}$
}

\author{
Esperrància: The Place of Waiting and Wandering
}

\author{
Fernando Freitas Fuão \\ Universidade Federal do Rio Grande do Sul. Brasil \\ Doi: https://doi.org/10.33975/disuq.vol10n1.476
}

$\Phi$

\section{Resumo}

Esse ensaio apresenta algumas possibilidades do pensamento sobre hospitalidade-acolhimento enunciado pelo filósofo Jacques Derrida. Considera a teoria dos Encontros na collage como um modo de avançar nas obscuras relações entre hospede e hospedeiro. Para tanto essas duas figuras são comparadas analogamente com as figuras da espera e da errância, conforme as apresentadas em A collage como trajetória amorosa. Procura-se mostrar que, a questão da hospitalidade tem a propriedade de unir as diferenças, porém conservando-as enquanto diferenças. Dessa maneira, a espera e a errância seriam consideradas entidades indissociáveis uma da outra.

Palavras-chave: Hospitalidade, Collage, Espera, Errância, Jacques Derrida.

\footnotetext{
" Recibido: 10 de febrero de 2021. Aceptado: 24 de marzo de 2021.

" Una versión previa de este artículo fue presentada en el Colóquio Internacional de Pós-Graduação em Desconstrução. Heranças e Promessas da Desconstrução. Organizado por la Facultad de Letras de la Universidad de Coimbra en octubre de 2014. Dicho coloquio fue organizado por Fernanda Bernardo.

Contacto: fuaofernando@yahoo.com
} 


\title{
Resumen
}

Este ensayo presenta algunas posibilidades del pensamiento sobre la hospitalidad-acogimiento propuesto por el filósofo Jacques Derrida. Se considera la teoría de los Encuentros en el collage como un modo de aproximarse a las oscuras relaciones entre huesped y hospedador. Para ello, esas dos figuras se comparan analogamente como figuras de la espera y de la errancia, conforme a las presentadas en $A$ collage como trajetória amorosa. Se busca mostrar que la pregunta por la hospitalidad tiene la propiedad de unir las diferencias, pero conservandolas en cuanto diferentes. De ese modo, la espera y la errancia se consideran entidades indisociables una de otra.

Palabras clave: hospitalidad, collage, espera, errancia, Jacques Derrida.

\begin{abstract}
This paper presents some possibilities of the thought about hospitality-welcoming enunciated by the philosopher Jacques Derrida. It considers the Theory of Encounters in collage as an attempt to advance in the obscure relationships between guest and host, placing in the analogs figures of waiting and wandering, as it was presented at my book called "The collage as loving trajectory". It seeks to show that the issue of hospitality - similarly the collage - has the property of joining the differences while keeping them. In this way, both the figure of waiting and wandering are treated as inseparable entities from each other.
\end{abstract}

Keywords: Hospitality, Collage, Waiting, Wandering, Jacques Derrida.

Cómo citar este artículo: Fuao, F. (2021). Esperrància: O lugar da espera e da errância. Revista Disertaciones, 10(1). https://doi.org/10.33975/disuq.vol10n1.476

\section{(c) $\frac{1}{\mathrm{BY}}$ () 9}

Material publicado de acuerdo con los términos de la licencia Creative Commons AttributionNonCommercial-NoDerivatives 4.0 International (CC BY-NC-ND 4.0). Usted es libre de copiar o redistribuir el material en cualquier medio o formato, siempre y cuando dé los créditos apropiadamente, no lo haga con fines comerciales y no realice obras derivadas. 


\section{Passagem}

As ideias de Jacques Derrida, principalmente a partir da questão da hospitalidade apresentaram-se como um potente elemento para compreendermos a cidade e arquitetura, não só para percebermos os lugares hospitaleiros e inóspitos; mas sobre tudo para nos abrir para um outro entendimento da arquitetura, onde as formas do acolhimento se traduzem em termos de abertura/fechamento, separação/união, recortar/colar, público/privado, familiaridade/não familiaridade. Não em seu sentido de oposição binária, mas que uma coisa está dentro da outra, ao ponto de ser indiscernível.

Enfim, o acolhimento se coloca como um desvelamento, um (de)voile, que nos permite vê-lo na arquitetura, na cidade, ou mesmo numa porta, ou banco de praça. Existe um sentido de acolhimento em todas as coisas no mundo, o importante é aprendermos a percebê-lo. A questão da hospitalidade, hoje, nos mostra quanto as grandes cidades estão se tornando cada vez mais inóspitas, e de quanto a arquitetura que é praticada, - fechando sobre o já fechado- corrobora com um isolamento que só insufla mais violência. O tema da hospitalidade mostra que lugares considerados hostis, inóspitos, sinistros são ainda capazes de acolher, e que pode haver ainda hospitalidade dentro da inospitalidade e viceversa. Curiosamente, a hospitalidade coloca o tema do espaço não no espaço, mas no indivíduo, como se ele próprio portasse a hospitalidade, o próprio espaço. Como se o sentido não estivesse no espaço ou na arquitetura, mas sim nas próprias pessoas, nas ligações afetivas, e para além das pessoas, na amorosidade; e esse talvez seja o primeiro sentido da arquitetura, apontado por Derrida.

Esse ensaio se alicerça nas semelhanças existentes entre o livro A collage como trajetória amorosa (2011) e as questões da hospitalidade e acolhimento apresentado por Jacques Derrida. Procuro mostrar similarmente através da collage que a hospitalidade parece seguir o mesmo movimento da trajetória amorosa descrita por Roland Barthes em Fragmentos de um discurso amoroso (1989), e da qual me apropriei para explicar o 
fenômeno dos 'Encontros' das figuras no livro A collage como trajetória amorosa (Fuão 2011).

Procuro mostrar aqui que as relações entre hospede e hospedeiro são análogas também a essas duas figuras centrais da collage: a espera e a errância como forma de reunir, colar, encontrar-se; aqui nomeada como esperrância, e que tanto a espera como a errância possuem formas e arquiteturas propícias a esses estados. Esperrância, simultaneidade da espera na errância, e da errância na espera, do um no outro. Uma Derridância que timpaniza uma cadência, que move o pensar para uma dança, uma colação também entre o francês e português que desdobra o sentido fazendo mais sentido; encadeamento de línguas, da minha e do outro na 'derridança'. Texto errante dançante, discurso decadente, décadanse que insiste em falar do amor e da amizade como conhecimento. Subjetividade última que conecta todos os pensamentos, atos e politicas humanas. Uma homenagem a Derrida, politicas da amizade e do amor.

\section{Collage e Acolhimento}

As maiorias dos estudos da collage/montagem sempre trataram de colocar a collage numa antinomia de oposição entre o recortar-colar, rasgar-costurar, desmontar-montar; ignorando que não há o colar sem o recortar, ou mesmo o importante intervalo significativo que se dá entre essas etapas. E nunca explicando como se dá a articulação das figuras no encontro delas; exatamente no meio dos dois extremos: entre o cortar e o colar, nesse lugar e instante que guarda segredos, entre a separação e o acolhimento.

Chamo de 'Encontro' na collage a relação recíproca envolvente entre figuras, objetos e corpos, ou do próprio ser frente ao outro, ou mesmo diante de sua representação. É sempre um movimento em busca do outro ou a espera do outro; encontrei esse 'movimento' em Fragmentos de um discurso amoroso de Roland Barthes. A Collage é acolhimento das diferenças, pura hospitalidade, a casa que recebe as figuras, recebe transformando, 'recebendo'. É o hostal das conjugações de figuras de tempos e topos distintos. Para Derrida 
esse receber, "só recebe na medida -de uma medida desmedida- em que ele recebe para além da capacidade do eu" (Derrida 1997 43).

Hospitalidade tal como concebeu Derrida pressupõe duas figuras centrais: o hospede e o hospedeiro, o convidado e o anfitrião (host, hoster). Em Barthes, encontrei essas mesmas duas figuras do hóspede e do hospedeiro, porem situadas poeticamente como 'o ser da espera' e o 'errante'. Espera e errância, um em direção ao outro, figuras próprias de uma aporia topológica, nem dentro nem fora, dentro e fora simultaneamente, interioridade que se realiza na exterioridade da outra, exterioridade na interioridade outra.

Assim como a collage que não se explica pela simples oposição recortar/colar; a hospitalidade também não pode ser explicada unicamente pela presença do 'eu' e do 'outro', do hóspede e do hospedeiro, pela separação/acolhimento. O acolhimento/recebimento é a primeira aproximação para essa compreensão, para ver o que acontece no mistério desse encontro. Não é possível pensar a hospitalidade sem o hospedeiro e hóspede, sem essa pessoa que espera a chegada do outro, a figura da espera, e desse outro que não vê a hora, ás vezes desesperadamente, de chegar a figura do errante. Essa é a mesma situação que funda a relação amorosa, a collage como trajetória amorosa.

É 'como se' o lugar que estava em questão na hospitalidade fosse um lugar que não pertencesse originalmente nem aquele que hospeda, nem ao convidado, mas ao gesto pelo qual um oferece acolhida ao outro mesmo; e sobretudo se este outro está sem morada. A amorosidade da collage se constitui na mudança de sentido de cada uma das figuras, entretanto salvaguardando sua singularidade. Sentido sem sentido, figuras que renunciam a si, querendo transportar-se velozmente para outra figura, morar na figura do outro. $\mathrm{Na}$ collage assim como na hospitalidade derridiana frequentemente ocorre deslocamento de uma figura para outra provocando mudança, 'andança' para acolher.

Hospitalidade, em termos físicos arquitetônicos, concretos, é dar lugar ao lugar, abrir o lugar, dar passagem, dar passo ao outro, abrir, acolher a diferença. Infelizmente nossas cidades se fecham cada dia mais, tornando-se hostis. A organização que caracteriza as grandes cidades tem sido basicamente a segregação espacial, esquadrinhamento, definição de usos (morar, trabalhar, circular e lazer proposto por Le Corbusier na Carta de Atenas (1933) no inicio do século XX; ou isolando-nos como se ainda estivéssemos no século 
XVIII, pestilentos; nos dois regimes de afastamento proposto por Foucault, em Vigiar e Punir: o da lepra - Exclusão, e o da peste - Disciplinaridades (Foucault 1977).

Mas, quando a 'diferenza' se desloca e entra no território do outro, e começa a intervir na vida desse outro, aí então, ocorre realmente uma mudança do espaço e da arquitetura. Quando ele desafia essa ordem secular, não só em seu sentido e uso, mas sobretudo na estrutura física desse espaço, aí então começa a hospitalidade e o 'desloucamento' dos sentidos, a destituição, a disseminação, a collage. Penso o acolhimento como uma afetividade perdida no tempo, fundadora da cidade; e que se desvela e se reinventa hoje também no espaço da informática, no mundo internet, nas figuras do host e do hoste, como bem descreveu juntamente com Anne Dufourmantelle em Da hospitalidade (2003).

A hospitalidade é o lugar que faz repensar a arquitetura, a casa, o abrigo. O lugar que dá lugar ao lugar. O sentido sem lugar que dá sentido ao lugar. No entanto, a cada dia mais nossos lugares em vez de se abrirem para os outros, de se prepararem para receber os outros, serem hospitaleiros, fecham-se em campos, em esferas, os quais necessitam de senhas, logins, ids e minados de câmeras para entrar. Esse 'outro' já não é mais aquele outro, que outrora batia na porta, como no mito grego, mas sim um 'outro outro', agora, impossibilitado de até mesmo bater na porta; porque o sentido da porta enquanto abertura ao outro esta se desvanecendo. A abertura é condição da hospitalidade, assim como o recorte é condição para collage, um lugar fechado nunca é hospitaleiro para quem fica de fora. $\mathrm{O}$ acolhimento é sempre abertura que se faz colando. Unindo. Acolhimento já é em si a abertura ao outro, esse primeiro 'sim', já é abertura. A abertura, ou o apagamento é abertura para a possibilidade.

O tema da hospitalidade, nos mostra que o 'campo' ou cercamento controlado, os condomínios fechados são por natureza um gerador de hostilidade. O campo separa, domestica, isola, excluindo tudo o que está fora e não tem acolhida, tal como a pobreza periférica. O campo exclui esses outros que estão de fora, que não podem entrar e nunca entrarão, são os fora do fora. Forasteiros dentro de sua própria cidade. A hospitalidade fica ameaçada numa cidade em que um grande número de pessoas não tem moradia, ou vivem em condições extremas de miserabilidade. Os arquitetos são educados a perpetuar 
desde cedo nas escolas esses modelos, criando paredes e mais paredes, cercas e mais cercas, linhas e mais linhas, zoneando. Importante lembrar que a linha, o traço (trait, trace) tanto une como separa, os de um lado e os do outro lado, os de dentro e os de fora. (De)fine.

\section{Esperrância}

Esperrância é o nome que entrelaça a espera e a errância. Esperrância, simultaneidade da espera na errância, e da errância na espera, do um no outro. Esperar na errância, errar na espera. Bordas, limites de uma situação em intermitente deslocamento. Esperança nativa na errância, esperrância, que se dobra na letra ' $\mathrm{R}$ ' prolongando ainda mais a espera. Esperança, 'esperância', em português se percebe ainda que essas palavras guardam o encontro da espera com a errância e a esperança; 'esper(a)nça' da espera com a andância, a (d)ança da espera e da errância. Esperançar. Penso a 'esperrância', também como um modo errante e errado de pensar o mundo, um pensar suspensivo onde o mundo todo poderia ser traduzido através dos locais de espera e dos locais de errância.

\section{A errância: o hóspede}

Hospitalidade é 'lugar sem lugar', que recebe o hóspede que vem de outro lugar, fora de tudo que conheço, fora de minha circunscrição. Sabe lá Deus de onde. O errante, o errado é sempre aquele outro que está normalmente de 'passo', na situação de passagem pronto para partir a qualquer momento, mas também propenso a permanecer definitivamente independentemente da vontade do hospedeiro. Ele é o incomodo que faltava no cômodo da casa do ser, a peça em questão, como se mostrou na filosofia até Levinas, ao propor uma ética da alteridade, uma ética e um pensar a partir do outro e não do eu. $\mathrm{Na}$ arquitetura ele é o que desorganiza a lógica da academia, do ensino, ele faz repensar o espaço, os lugares, o próprio conceito de casa, a morada do outro, a outra morada. Ele é um apagador 


\section{Fernando Freitas Fuão}

por excelência da escrita acadêmica, o outro retraça não somente na arquitetura, mas em varias outras áreas do conhecimento. Como definiu Barthes:

O outro vive em eterno estado de partida, de viagem; ele é, por vocação migrador, quanto a mim, que amo, sou por vocação inversa, sedentário, imóvel, disponível, à espera, ficando no lugar, não resgatado (en souffrance) como um embrulho num canto qualquer da estação. A ausência amorosa só tem um sentido, e só pode ser dita a partir de quem fica, e não de quem parte: eu, sempre presente, só se constitui diante de você, sempre ausente. Dizer a ausência é, de início, estabelecer que o sujeito e o outro não podem trocar de lugar Barthes (1981 27).

O Encontro do errante e daquele que espera, o encontro dos dois, das diferenças conservando as diferenças é o que faz o lugar. Não é o lugar que propicia o encontro, mas é o encontro em si das pessoas que cria o lugar, a coalescência: a ciência do grude da vida, E como não existe pessoas sem o lugar, se tornam então indissociáveis.

A essência da cidade grande é esperar a chegada dos outros. A cidade vive nessa eterna espera, é na indefinição, nas bordas, nas bordas do tempo, na periferia, nas zonas fronteiriças, nesse cinza onde se localizam as potencias dos lugares do acolhimento. É nas bordas que se faz a junção, a costura. Por exemplo, na collage as figuras ao se juntarem, fazem seu próprio lugar e existência, uma analítica da existência na conjunção das singularidades das figuras. É 'como se' o encontro se realizasse dentro, no interior da figura da espera, na casa do hóspede, mas também aporéticamente também 'como se' realizasse no interior da figura do errante, no transbordamento do um no outro, no dentro do fora, no fora do dentro. O um no outro, em nenhum simultaneamente. O errante erra por sua condição de abandono, abandono dos outros, abandono de si mesmo. E o errante acolhe, muitas vezes, mesmo sem morada, sem esperar, acolhe não esperando, acolhendo esperando quase nada, como os moradores de rua. O lugar é 'doutro', do outro de outro lugar, do sem lugar, do sem-teto.

No acolhimento as formas estão sempre se fechando e abrindo-se como num jogo de dobras e desdobramentos, como o caso das enseadas na natureza. A hospitalidade é abertura, vazão, interioridade, porta aberta, entre aberta para a entrada do outro. Vivo no outro, vivo na loucura de não habitar em mim mesmo. 
Collage é indefinição, amorosidade que não tem fim, geração, movimento de aberturas e grudes entre as figuras. Quando o errante, o outro, o estrangeiro entra em casa, entra no jogo do sentido, se faz existência graças a seu hóspede. Tal como a porta que se abre para dentro, para o de fora adentrar-se.

Uma figura mora na outra, 'na mora da' outra. O outro é o lugar. O errante, o errado, seu corpo e seu tempo.

Agora, é o tempo do outro que assalta a modernidade e suas velocidades. O outro tempo, outrora. 'Outra-hora' não quer dizer passado, mas simplesmente outro tempo, que nada mais é que, o 'tempo do outro', que chega para desestabilizar a lógica da geração. O tempo já é outro.

O outro é sempre um outro espaço, um outro lugar, um outro tempo, um síngulo. Tal como um fragmento na collage que arrasta sua imagem/espaço e seu tempo. A figura errante na collage é sempre um desvio, um detournement no uso do espaço e do tempo. Quando o errante chega, quando se encosta, quando se cola ao lado, ou encima ou por baixo, desdobra o sentido da coisa em outra coisa, transborda. O errante, o errado vive sempre a esperança de modificar a situação em que se encontra errando, e o 'esperante' sempre a espera que alguém the modifique a situação em que se encontra. Subestimar a duplicidade e cumplicidade nesse jogo, entre a espera e a errância é cair no acolhimento romântico. Não é só o errante, o enlouquecido em questão, mas também a figura da espera na collage está sempre enlouquecida, desesperada, fixada no tempo e no espaço, colada, imobilizada em sua loucura. Quando ele abraça mesmo o outro, quando ele abraça a loucura sorrindo, quando a loucura abraça a loucura, quando se abre recebendo, quando se rasga desdobrando-se, quando vira abraço: aí então se cria o lugar.

O errante é o que traz a outra linguagem, ele não fala a mesma língua, ele fala tudo errado e errante. Ele é a presença que revela a figura como ser aberto, modificando o lugar e a arquitetura. Para Barthes a Errância é a capacidade humana de errar, vagar em busca do corpo amado, da figura amada. Mas a hospitalidade de fato, a hospitalidade dentro da cidade, a que ocorre no dia a dia, distante da teoria, mostra que 'quem' realmente hospeda o errante, o estrangeiro, não é o ser da espera que tem sua casa própria, seu chez moi, mas ao contrário: são os errantes, os estrangeiros, os clandestinos, os pobres que vivem na 
periferia que ali chegaram antes e fizeram um lugar de hospitalidade. O principal lugar de acolhimento na cidade não é o centro, mas sim a periferia, as bordas da cidade. O errante, assim, acolhe o errante. O errante que anteriormente chegou já se tornou espera, já se fez casa, está colado ao lugar, se fez espera na borda, na periferia nua das grandes cidades. Ele acolhe quase em sua impossibilidade de acolher, muitas vezes para além das condições de acolhimento mínimo.

Assim, toda a errância contém uma espera e toda espera contém uma errância, daí a esperrância. De um se passa para o outro com muita facilidade. Assim analogamente, como disse Derrida, da hospitalidade se passa facilmente para a hostilidade, e por isso criou a expressão 'hostipitalidade'.

\section{A espera, o hospedeiro}

O mundo (a)guarda. Tudo está errantemente esperando, aguardando. Diz Barthes: "Espero uma chegada, um regresso, um sinal prometido. Pode ser fútil ou terrivelmente patético: na espera, eu não espero senão um toque do telefone, mas a angústia é a mesma. A espera é sempre solene, ou seja, é sempre um estado de suspensão, porque a espera é a mais devota aprendizagem" (Barthes 1981 94).

Se a errância existe é porque algo, alguém espera ou vai esperar. Não existe errância sem espera, todo errante espera chegar em algum ponto; assim como não há espera sem a esperança da chegada de algo ou alguém. Ambos compartilham no ponto comum da chegada final. Espero no estacionamento, a sinaleira me faz esperar, parar; espero na sala de espera, no consultório, no escritório, espero na fila, espero na parada de ônibus. Me esperam, me faço esperar, espero sempre. A espera disciplina a própria condição para esperar. A docilização dos corpos, a domesticação humana é feita de espera, a espera molda o comportamento, retira o lado selvagem através do cessar da agitação. A espera disciplina, ela é controladora e controlada. Barthes, nos mostra que a espera é uma condição que só a mim toca, "O outro parece não esperar nunca. Ás vezes, quero representar aquele que não espera; tento me ocupar em outro lugar, chegar atrasado; mas 
nesse jogo perco sempre: o que quer eu faça, acabo sempre sem ter o que fazer, pontual, até mesmo adiantado. A identidade fatal do enamorado não é outra senão: sou aquele que espera" (Barthes 1981 96).

Descobri esse sentido da espera fazendo collages, nela também existe uma cenografia da espera: a figura papel, figura de fundo, a primeira figura que se coloca como chamariz, figura destinada a esperar a chegada das outras para fazer novo sentido, sentimento. A espera é uma querência, uma sala de espera para as demais. A figura da espera é um argumento narrativo. Figura inicial, receptáculo das demais, corpo anfitrião que hospeda os demais corpos, que hospeda a si mesma ao sitiar-se, situar-se. O hospedeiro, a hospedeira é ser esperando, encantada, imobilizado. Ele não faz nada, só aguarda, guarda, res-guarda, fica agua(r)dando, aguardado como uma ilha, uma isola, isolado, aguardando um barco, ou um náufrago.

A espera é sempre um delírio, é 'embrulhada', envelopada, sofrida mesmo. Faz-se de tudo para disfarçar esse estado de agonia da espera. Diz Derrida, em uma das mais belas passagens Da hospitalidade:

O dono da casa 'espera com ansiedade sobre a soleira de sua casa o estrangeiro que ele verá despontar no horizonte como um libertador. E do mais longe que ele vir chegando, o senhor se apressará em gritar-lhe: 'entre rápido, porque tenho medo de minha felicidade ... Entre rápido, rápido, quer dizer, sem demora e sem esperar. O desejo é a espera daquele que não espera. O hospede esperado, não é apenas qualquer um a quem se diz 'venha', mas 'entre', entre sem esperar, faça uma parada entre nós sem esperar, venha para dentro, venha a mim, não apenas para mim, mas em mim: ocupa-me, toma lugar em mim, o que também significa tome o meu lugar (Derrida 2003 107).

O desejo da espera é sempre acabar com a aflição, absorvendo esse outro, aguardando, para guardá-lo, retendo para devorá-lo, seu desejo é ser nele, ser nela. A espera sempre é puro desejo, e o desejo não vive sem a espera. A espera é sempre um delírio, assim retratou Barthes com o pequeno conto do mandarim. "Um mandarim se apaixonou por uma cortesã. 'Serei tua, disse ela, depois que passares cem noites me 
esperando sentado em um banco, no meu jardim, sob a minha janela'. Mas na nonagésima nona noite, o mandarim se levanta, pega seu banco e se vai" (Barthes 1981 96).

Não há nada de errado na errância. Não é só o hospedeiro que espera, o errante também espera, numa simetria quase equivalente, ambos esperam cada um a seu modo. Tudo espera. Tudo espera errando errantemente. A espera vaga em seus pensamentos, erra de pensamento em pensamento, sem cessar. Eu mesmo me espero, eu mesmo tenho que me esperar, antes de nada. Segundo Derrida, "esperar-se nos limites, esperar-se a encontrar com os limites e esperar-se um mesmo nos limites, estar citado consigo mesmo nesse lugar, nessas paradas que se denominam 'os limites da verdade', nas proximidades desses limites" (Derrida 1996 117).

O efeito negativo dessa espera é o desespero e a angústia. O efeito positivo é a esperança, mas a esperança ativa. O surpreendente, o acontecimento surge do aparecimento de um sentido inesperado. A existência desse sentido que surge de repente destrói o sentido primeiro esperado, é como se o porvir destruísse o futuro presente. Decepcionar a espera é colocar a possibilidade de um sentido razoável como horizonte, e surpreendê-la logo com outro sentido que não encaixa nos limites da razão que justificava o fato de esperar. Ao contrario do pensamento da espera é todo previsível.

Importante ressaltar que a lógica moderna das relações masculino-feminino e todo leque que esse abre entre os dois extremos de gênero tem demonstrado que se alternam constantemente entre sexos, não há um ser predefinido por uma feminilidade que espera, tampouco um ser destinado a errância por sua masculinidade. Curioso por que Barthes também observou desse errôneo atributo falocêntrico:

Historicamente, o discurso da ausência é sustentado pela mulher: a mulher é sedentária, o homem é caçador, viajante; a mulher é fiel (ela espera), o homem é conquistador (navega e aborda). De onde resulta que todo homem que fala a ausência do outro, feminino se declara: esse homem que espera e sofre, está milagrosamente feminizado. Um homem não é feminizado por ser invertido sexualmente, mas por estar apaixonado (Barthes 1981 45). 
O primeiro acolhimento é o da mãe natureza, da terra como bem observou Heidegger em Habitar, construir, pensar (1954), o ser nunca será uma casa exatamente, o homem é um ser destituído de morada, sua morada é ser ponte, conexão, cola, colli; ou mesmo não ser nada, não ter morada fixa. O ser que acolhe, cola, é aquele que se situa na porta, na abertura, no umbral, no vão dos sentidos e sentimentos, no recortado de seu sorriso, nos braços abertos, na mão estendida, aberta 'en la mano' estendida, en lo (hu)mano. A cola e o 'com-tato'. O acolhimento é a abertura, o corte à dimensão humana, ao hu main. E a cola é o grude amoroso na collage, sua máxima: o 'contato'.

\section{Contato}

A mão, ela e sua palma, sua planta e seus dedos, sua concavidade de recebimento e recolhimento, sua abertura e fechamento. $\mathrm{O}$ acolhimento no entre dedos, no ' $\mathrm{V}$ ' e no ' $\mathrm{U}$ ', em suas cavas, no entrelaçamento dos dedos das mãos, no agarrar das mãos. A questão do 'hu-mano' passa pela questão da mão, do tocar (toucher), do toque como bem apresentou Derrida em El tocar, Jean-Luc Nancy (2011); também pode se considerar como uma questão de dobra, das dobras da mão, similar El pliege (1989) de G. Deleuze. A mão e sua conformação, pontas que se abrem, dobram para a cavidade do acolhimento ascentente descendente. Na mão a demonstração da abertura e fechamento. A mão é criação, entretanto que a mão produz mascara, seu proprio significado, seu sentido. A mão produz a casa, a cidade, mas a casa e a cidade ocultam todo esse trabalho da mão, oculta a propria natureza do ser. Quando olhamos a cidade não vemos o trabalho da mão, da mão de obra. A mão é o sentido, o sentimento do humano, e o trabalho que ela realiza é a propria economia, oikos, a propria casa, a propria posse. A questão da morada passa pela mão, pela economia e pela politíca da mão. O mais proprio do próprio talvez esteja também na mão.

O exercício de aplicá-la, calcá-la sobre uma superficie, ou o exercicio de contornar seus dedos a lapis, como se fosse um territorio do proprio, configura-se a primeira 
cartografia, mapa. É no espaço dos entre dedos que a criança começa a se conhecer e conhecer o mundo. A mão mesmo antes da fisionomia do rosto é portadora da identidade, a maneira mais imediata de auto representar-se, assim como nas pinturas rupestres da antiguidade. É nesse 'entre', entre dedos, entre mãos, nem dentro nem fora, em lugar nenhum físico, entre o um e outro que se abre o acolhimento; ou mesmo no gesto da mão que se abre que acolhe o ir-mão, como na 'mano de lo humano', no humain, no humano toque, no toucher, na máxima da collage: o contato, 'com o tato'.

A mão em seu sentido de abertura é uma das formas de acolhimento. Na figura da mão do hu-mano, encontram-se uma serie de formas, de curvaturas do acolhimento que também são encontradas na natureza. Dependendo do grau de abertura essas dobras, curvas podem se apresentar quase como imagens de uma estranha geográfica das concavidades: a baia, a enseada, a fenda, o ' $\mathrm{V}$ ', o ' $U$ ', a abertura, a angustura, o estreito, a meia lua, o croisaint, a invaginação. Refiro-me aqui a potência mesmo das formas côncavas, as dobras encontradas com grande expressão nos limites da natureza, nas bordas da natureza que suscitam flexões, 're-flexões', no encontro da agua e da terra, como por exemplo: nas enseadas e nas baias, descritas em As formas do acolhimento (Fuão 2014).

O espaço e as formas do acolhimento partem do sentido de acolhimento contido na palavra 'cola', expressão adotada por mim para designar esses vários sentimentos de união e contato que o acolhimento/hospitalidade pressupõe, e que aparecem em várias palavras derivadas como: collé, colli, a(colher); enfim, que podem ser entendidas como uma afeição, uma feição, uma maneira de fazer algo que acolhe. O acolhimento, a ação de colher, deriva desse 'colher'; esse colli-gere latino tem relação justamente, com a origem da religação; Heidegger em Habitar, Construir, pensar (1954) empregou o colli como ligação, como ponte mesmo para explicar o dasein. Acolhimento (accueil) é a ação de acolher, da cola, do colar e da collage. Mas não só esse sentido, esse 'colher' enquanto sufixo cola, também designa uma 'ura', um cultivo (agrícola, vinícola), uma cultura, um trato; refere-se, portanto, à colheita, a criação, o cuidar, e a colaboração.

Colher, morfologicamente, é a concavidade, a dobra, a dobra do corpo tensionado que se dobra e se desdobra continuamente para acolher o outro. O recipiente aberto, tal qual a colher mesmo (utensílio). (A)colher. Curiosamente, a palavra collage tem também 
suas origens nesse colli; na palavra latina colligare que significa unir, colar, do qual também deriva o conceito de coleção, coligação, colaborar, coligir (reunir o que está esparso, disperso). Mas se observarmos, quando se passa da palavra ao verbo, da cola ao colar, suas contas se estendem, remetendo-nos ao próprio colar como insígnia que circunda guardando. Assim também poderíamos nos remeter ao verbo imaginário colegare (colligare), os colegas, os amigos, aqueles que andam juntos. De certa forma o significado da cola se próxima ao próprio 'símbolo'. Simbolum: unir, congregar, conectar o acimaabaixo, ligar todas as coisas. A linguagem simbólica permite a circulação de um nível a outro, integrando todos estes níveis, mas sem fundi-los. Etimologicamente 'símbolo' do grego (syn e tobalein) significa, também, ir juntos, aventurar-se juntos tal qual o sentido da collage.

\section{Por vir}

A collage apareceu aqui como expressão metafórica de uma ética da alteridade, e procurou-se mostrar que essa ética da alteridade, do acolhimento tem fortes implicações com seu modo de produção: sua (po)ética. Ou seja: a collage mostra-se como arte de acolher (colli) diferenças conservando-as enquanto diferenças. A collage, assim como o encontro no acolhimento convida as figuras a narrarem outras histórias, distintas daquelas a que foram destinadas inicialmente; ou que representavam inicialmente. Os Encontros se conjugam quase sempre em termos topológicos divergentes, distintos, onde a visão do outro, a minha e a dos demais coexistem numa multiplicidade de referentes perceptivos espaço-temporais. O Encontro é puro espaço de dois ou mais corpos no mesmo espaço. Tal atividade criadora funda os vínculos que anulam, temporariamente, todo o distanciamento estabelecido pela sociedade das especialidades, da fragmentação. Mas o que haverá de comum nessas figuras, nesses indivíduos a não ser as bordas de cada tempo, de cada um ao lado do outro, dentro do outro? Onde para cada situação espacial, sempre haverá uma borda, uma tênue linha que definirá, com a mais precisa imprecisão, os estados 
do ser, do espaço e do tempo. A organização dos seres, dos grupos, dos comuns e das constelações e da collage, estão submetidas ao acaso, ao acontecimento, e não pode ser explicada pela lei da linearidade que impõe repressão, como até hoje vem sendo afirmada. É nesse sentido que o movimento amoroso, dinâmico da collage e da hospitalidade pode servir de estrutura e lei motivadora para existência de uma livre organização baseada no acoplamento dos indivíduos e das multidões, como descrito em As bordas do tempo, a idéia de collage em Antonio Negri (Fuão 2012).

O amor não é nenhuma redenção, é apenas uma outra lógica; também limitada, que rege a organização dos corpos, a ligação da vida. Para a collage, assim como para o acolhimento o que está em jogo não é só o resultado das forças produtivas, o econômico, o capital, o resultado dos acoplamentos - pois este é irrelevante enquanto produto, que só tem seu valor no potencial de continuidade; mas sim na capacidade do amor enquanto gerador de potencial. É essa espécie de 'amorosamento', amância entre figuras, entre corpos, entre comuns diferentes, entre diferentes comuns que forma a imensa collage que permeia e invade todos, com um sentimento inovador, criador.

Cabe ainda interrogar, que hospitalidade é essa do Estado que governa nossas vidas desde o nascimento até a morte, e não oferece morada, acolhimento a quem precisa? O que esperar em troca quando não se tem nada para dar, muito menos uma casa para retribuir sua acolhida, o que esperar dos sem-teto, dos errantes, quando não se tem sequer comida para compartilhar? Entretanto, paradoxalmente, a hospitalidade é mais visível e mais bela ali onde falta tudo. A hospitalidade/acolhimento faz parte da ética da alteridade anunciada por E. Levinas em Totalidade e Infinito (1980) e J. Derrida em Adeus Levinas (1997). A collage se manifesta como uma estética dessa ética. Como disse Solis, "o ethos, o ético, é visto como a morada, a casa, a rua e a cidade segundo o âmbito da acolhida do Outro. O que tomamos por ético, portanto, é apenas o horizonte de aparecimento da alteridade que, ao invés de compreender a hospitalidade dentro de condições restritas e acabadas, será o espaço da incondicionalidade, o espaço do acolhimento irrestrito ou sem condições" (Solis 2018 17).

Finalmente, a lógica da collage não é mais a do poder instituído, de qualquer espécie, não é mais do artista criador, demiúrgico. Nela, estamos numa operação em que nada faz 
sentido, ou seja, que o sentido só é obtido através das maravilhosas conjunções dos outros e com os outros. A noção de hospitalidade, traz consigo a ideia de uma democracia por vir, ou seja, sem hospitalidade não pode haver nenhum tipo de democracia. Entretanto, as democracias existentes limitam e muitas vezes expurgam toda e qualquer hospitalidade pretendida. Por isso, também para a collage não se trata somente de uma figura estar junta a outra, colada, mas sim e sobre tudo de uma intenção que une a todas e a todos; e os impede de desintegrar-se em diálogos soltos, dispersos, ou vivências individuais.

\section{Referencias}

Barthes, Roland. Fragmentos de um discurso amoroso. Rio de Janeiro: Francisco Alves, 1981.

Barthes, Roland. Fragmentos de um discurso amoroso. 7ed. México: Siglo Veintiuno editores, 1989.

Deleuze, Gilles. El pliegue, Leibniz y el barroco. Barcelona: Ediciones Paidós, 1989.

Derrida, Jacques. Adeus Levinas. São Paulo: Editora Perspectiva, 1997.

Derrida, Jacques. Apories, Mourir - s'attendre aux 'limites de la vérité'. Paris: Galilée, 1996.

Derrida, Jacques; Dufourmantelle, Anne. Da Hospitalidade. São Paulo: Editora Escuta, 2003.

Derrida, Jacques. El tocar, Jean-Luc Nancy. Buenos Aires - Madrid: Amorrortu, 2011.

Fuão, Fernando. "As formas do Acolhimento". Em: Solis, Dirce; Fuão, Fernando (Orgs.) Derrida e arquitetura. Rio de Janeiro: EDURJ, 2014

Fuão, Fernando. "Construir, morar, pensar; uma releitura de Construir, habitar, pensar de Martin Heidegger". Revista de Estética e Semiótica (RES) 5/2, 2015: 71-82. Disponible en: http://periodicos.unb.br/index.php/esteticaesemiotica/article/view/19597/0

Fuão, Fernando. "As bordas do tempo, a idéia de collage em Antonio Negri". 2012. Disponible en: https://fernandofuao.blogspot.com/2012/10/as-bordas-do-tempo-ideia-decollage-em.html 


\section{Fernando Freitas Fuão}

Fuão. Fernando. A collage como trajetória amorosa. Porto Alegre: Editora da UFRGS, 2011.

Foucault, Michel. Vigiar e Punir: história da violência nas prisões. Petrópolis: Vozes, 1977.

Heidegger, Martin Construir, habitar, pensar. Trad. Márcia Sá Cavalcante Schuback [Bauen, Wohnen, Denken]. Conferência pronunciada por ocasião da "Segunda Reunião de Darmastad". En: Vortäge und Aufsätze, G. Neske, Pfullingen, 1954. Disponible en: www.prourb.fau.ufrj.br/jkos/p2/heidegger_construir,\%20habitar,\%20pensar.pdf.

Le Corbusier. A Carta de Atenas. (Tradução e apresentação Roberta Scherer) São Paulo: Edusp, 1993.

Levinas, Emmanuel. Totalidade e Infinito. Lisboa: Edições 70, 1980.

Solis, Dirce; Fuão, Fernando. “Da dimensão ético-política e sua relação com a democracia por vir na arquitetura". PIXO, revista de arquitetura, cidade e contemporaneidade 2/5: 1625.

Solis, Dirce; Fuão, Fernando (Orgs.) Derrida e arquitetura. Rio de Janeiro: EDURJ, 2014. 